\title{
PERAN PENGAWASAN LEMBAGA TERHADAP SANTRI DALAM PENGGUNAAN TEKNOLOGI DI ERA DIGITAL PADA YAYASAN BANI ABBAS
}

\author{
${ }^{1}$ Subarto, ${ }^{2}$ Ugeng Budi Haryoko \\ Dosen Pascasarjana Universitas Pamulang \\ Email : 1. subarto67@gmail.com
}

\begin{abstract}
ABSTRAK
Peran serta santri dan pesantren dalam menghadirkan penggunaan teknologi informasi yang baik harus lebih ditingkatkan. Kemajuan era digital yang sudah menyentuh hampir seluruh masyarakat harus mendapat pendampingan yang baik agar tidak ada penyalahgunaan. Sudah saatnya pendidikan di pesantren memanfaatkan kemajuan teknologi digital. Banyak platform media sosial yang dapat digunakan sebagai media pendidikan yang kreatif dan inovatif pembelajaran secara digital harus dibangun di pesantren sehingga dapat mengajarkan mereka untuk memanfaatkan kemajuan teknologi digital secara positif. Tujuan kegiatan ini adalah untuk memberikan penyuluhan terkait peran pengawasan lembaga terhadap santri dalam penggunaan teknologi di era digital pada Yayasan Bani Abbas.

Metode pelaksanaan adalah dengan memberikan penyuluhan terkait pentingnya penguasaan teknologi di era digital dengan memperhatikan kaidahkaidah kesantrian, karena teknologi tidak hanya memberikan manfaat tetapi juga ada beberapa efek negatif yang ditimbulkan.

Hasil kegiatan ini diharapkan para santri dapat memanfaatkan teknologi sesuai dengan kebutuhan tanpa meninggalkan kewajiban sebagai santri yaitu mengamalkan ilmu agama sesuai dengan visi dan misi Yayasan Bani Abbas.
\end{abstract}

\section{Kata Kunci : Pengawasan, Teknologi, Era Digital.}

\section{PENDAHULUAN}

Yayasan Bani Abbas pada mulanya hanya sebuah tempat pengajian dan pengajaran Al-Qur'an dan ilmu keagamaan yang sederhana untuk warga sekitar kediaman Ust.Muhtadi .M.Pd.I. Berdirinya Yayasan Bani Abbas ini dilatarbelakangi oleh semakin banyaknya murid dan anak didik pengajian Bani Abbas yang menjadi yatim piatu karena wafatnya orang tua mereka.Maka untuk menjaga kelangsungan kehidupan,sekolah dan pendidikan mereka. Ust. Moh. Muhtadi. M.Pd.I mulai memikirkan untuk memberikan bantuan / santunan untuk mereka. Maka dikembangkanlah pengajian sederhana ini menjadi sebuah Yayasan yang bergerak dibidang sosial,pelayanan masyarakat dan pendidikan agama.

Yayasan Bani Abbas memiliki visi : Menjadikan Yayasan sebagai lembaga sosial dan pendidikan yang dapat mengangkat harkat dan martabat kaum dhu'afa serta anak yatim piatu. 
Misinya adalah: Menghasilkan anak santri yang memiliki kemampuan dasar dibidang agama khususnya Al-Qur'an dan umum yang memadai; memberikan anak santri bekal ketrampilan yang cukup supaya mampu hidup mandiri dikemudian hari; memberikan bantuan dan santunan bagi para santri yatim piatu dan fakir miskin; menyiapkan anak santri menjadi anggota masyarakat yang memiliki akhlaq yang mulia dan berguna bagi lingkungannya; menghasilkan para santri yang hafidz Al-Qur'an dan mengembangkan kualitas anak santri melalui berbagai bentuk pendidikan dan ketrampilan.

Jumlah Santri didalam panti sementara baru ada 11 dan akan selalu bertambah sampai batas yang tidak di tentukan dan non panti ada 75 santri dan non panti serta kaum dhuafa.

Penggunaan teknologi di era digital sangat banyak manfaatnya dan juga efek sampingnya, oleh karena itu perlunya pengawasan dari pihak lembaga agar para santri bisa menyeleksi atau memilah-milah apa saja yang bisa menjadi manfaat dan menghindari efek negatif dari teknologi tersebut.

\section{METODE PELAKSANAAN KEGIATAN}

Metode pelaksanaan adalah dengan memberikan penyuluhan terkait pentingnya penguasaan teknologi di era digital dengan memperhatikan kaidahkaidah kesantrian, karena teknologi tidak hanya memberikan manfaat tetapi juga ada beberapa efek negatif yang ditimbulkan.

Tahap pertama : Dosen pengabdi berkoordinasi dengan kepala lembaga bani abbas, para mahasiswa dan para santri

Tahap kedua : Dosen pengabdi melakukan pembinaan dengan memberikan penyuluhan

Tahap terakhir : Dosen pengabdi mengadakan evaluasi atas kegiatan yang telah dilakukan

Kegiatan diadakan di Yayasan yatim Piatu Bani Abbas, Yayasan Bani Abbas. Pondok Pesantren Tahfidz, Panti Asuhan Yatim dan Dhuafa. Jln. SD. Inpres, No. 1., Rawa Lele Jombang Tangerang Selatan Tlp. 021-96549158 081536853856

\section{HASIL DAN PEMBAHASAN}

Di zaman era informasi dan teknologi seperti sekarang ini, segala jenis informasi bisa dengan mudah di akses oleh setiap orang dimanapun dan kapanpun, baik muda ataupun tua, orang desa maupun kota semua elemen masyarakat bisa dengan mudah mendapatkan informasi yang hendak mereka cari, meskipun info tersebut lingkupnya hingga luar negeri semua bisa didapat dengan waktu hitungan jari.

Berkembangnya teknologi juga harus di imbangi dengan tingkat intelektualitas seorang, agar segala informasi yang dengan mudah di dapat di serta merta di telan dan di terima akal tanpa melalui filterisasi informasi, karena tidak menutup kemungkinan informasi yang bertebaran di dunia maya adalah seratus 
persen real adanya, maka dari itu manusia yang bijak adalah ia yang selektif dalam menerima segala bentuk informasi yang ada.

Begitupun untuk santri, meskipun santri adalah dia yang tinggal di penjara

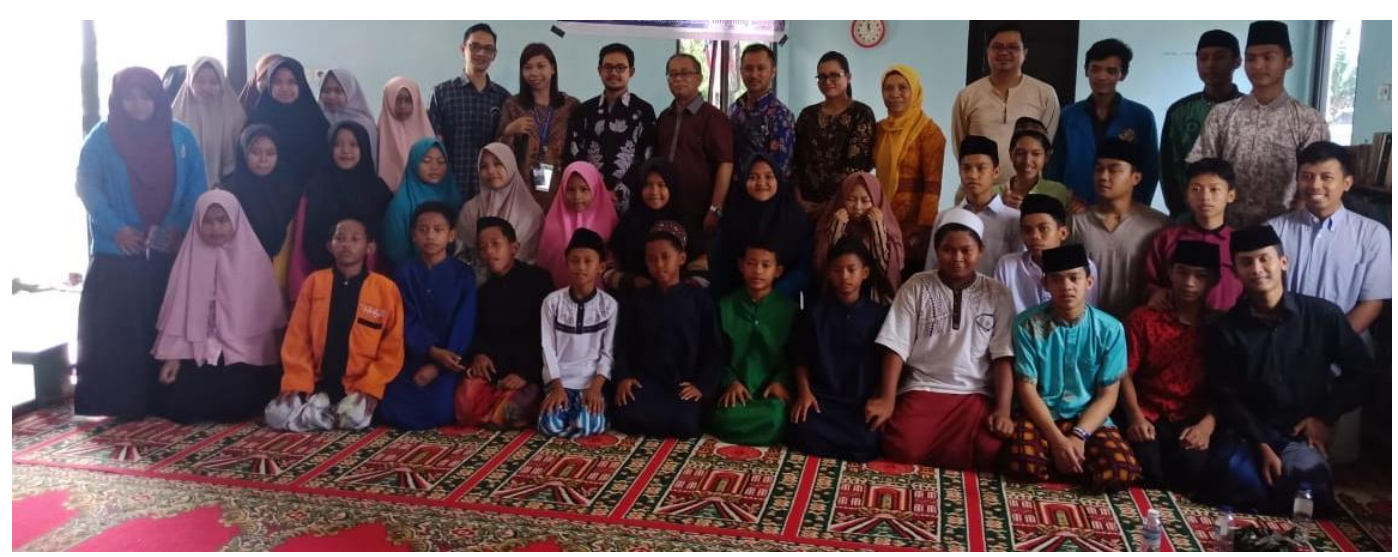

suci dan hidup serba di batasi, akan tetapi alangkah lebih indah dan baik jika hal tersebut tidak menjadi halangan untuk berkreasi dan tetap update informasi. Karena santri merupakan pribadi yang memiliki spiritualitas, intelektualitas serta memiliki sikap sosial yang tinggi, maka sangat penting bagi santri untuk ikut berpengaruh dan ikut andil dalam menyebarkan informasi baik di dunia nyata maupun di dunia maya, karena semua itu sudah berkaitan dengan yang namanya teknologi, santripun harus melek tentang dunia teknologi dan informasi, karena santri adalah agen risalah kenabian yaitu orang-orang yang dipersiapkan untuk membina masyarakat.

Tak dipungkiri akhir-akhir ini peran santri sudah dinanti-nantikan oleh masyarakat untuk membawa perubahan dan menggerakkan masyarakat kearah yang lebih baik, karena sekarang banyak timbul keresahankeresahan yang di timbulkan oleh kesalah pahaman tentang suatu ajaran maupun informasi yang beredar, maka dari itu apabila santri katro dakwah pun akan KO. Kerana di zaman sekarang media perang sesungguhnya adalah teknologi melalui internet ataupu dunia maya, bukan lagi bersaing dalam medan perang seperti zaman-zaman dahulu.

Maka santri sebagai individu yang berilmu terutama

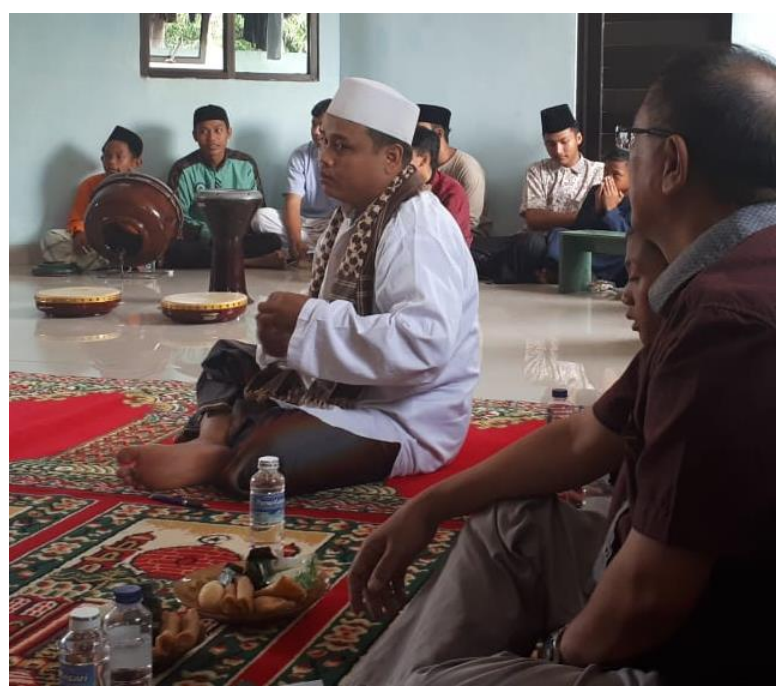
dalam bidang agama akan tetapi tidak menutup kemungkinan mumpuni juga di bidang-bidang ilmu lainnya, sehingga agar mampu bersaing dan berpengaruh dalam sejarah merubah peradaban santri juga harus melek teknologi. 
Teknologi dapat berfungsi sebagai alat peningkat produktivitas dalam bekerja maupun belajar.sekarang banyak bermunculan jenis pekerjaan baru yang bertumpu pada teknologi.Bahkan belajar maupun bekerja terkadang mencapai hasil memuaskan dibandingkan dengan cara yang manual.

Pada Zaman dulu sebelum teknologi berkembang pesat seperti saat ini,sudah banyak juga santri maupun pelajar yang inovatif dan kreatif.Tetapi untuk menghasilkan sebuah hasil,mereka membutuhkan waktu yang cukup lama karena kurangnya dukungan teknologi.Sekarang ini berkat dukungan teknologi,semakin banyak inovasi dan kreasi dalam berbagai bidang yang dapat memudahkan dan menjadi kunci penentu para santri dalam proses pembelajaran.

Pada masa sekarang dimana teknologi sedang melaju dengan begitu cepat,kalau kita terlambat kita hanya akan menjadi penonton dan korban yang mudah dimanfaatkan.Banhkan lebih ekstrim lagi kita bisa dijajah oleh golongan tertentu.Tetapi kalu kita mampu mengendalikanya kita dapat mengendalikan peradaban dan membangun umat dan dapat berandil pula dalam menciptakan teknologi yang canggih.

\section{KESIMPULAN DAN SARAN}

Hasil kegiatan ini diharapkan para santri dapat memanfaatkan teknologi sesuai dengan kebutuhan tanpa meninggalkan kewajiban sebagai santri yaitu mengamalkan ilmu agama sesuai dengan visi dan misi Yayasan Bani Abbas.

\section{DAFTAR PUSTAKA}

http://mohammadmuhtadi.blogspot.com/2013/02/profil-yayasan-bani abbas $12 . h t m l$

Subarto, S., Sugiarti, E., \& Irmal, I. (2018). Pemberdayaan Perempuan Dalam Meningkatkan Perekonomian Keluarga Pada Warga Legok Ngenang Kabupaten Bogor. Jurnal Pengabdian Dharma Laksana, 1(1). 